\title{
An unusual case of congenital unilateral Coats's disease associated with morning glory optic disc anomaly
}

\author{
I KREMER,' S COHEN,' R BAR IZHAK, ${ }^{2}$ AND I BEN-SIRA ${ }^{1}$ \\ From the 'Department of Ophthalmology, Beilinson Medical Center, Petah Tiqva, Israel; and the \\ ${ }^{2}$ Laboratory' of Eye Pathology, Assaf Harofe Hospital, Israel
}

SUMMARY We present the case of a 13-year-old girl with a right congenital esotropia who at the age of 6 months presented an anomaly of the optic disc and retinal vessels in the same eye. In the following year she developed Coats's disease, rubeosis iridis, and neovascular glaucoma that led to enucleation. Pathological examination confirmed the clinical diagnosis.

One of the most interesting retinal vascular diseases, the pathogenesis of which is still controversial, is Coats's disease. ${ }^{\prime}$ The classical features common to this disease are: the comparatively young age of the patients, the absence of any systemic disease, the high unilateral incidence of the ocular disturbances, and the insidious onset and slow progression. ${ }^{2-7}$ Coats's disease may be confused with retinoblastoma. Most of the histopathological data on this entity have come from enucleated eyes, especially in children under the age of 4 years. ${ }^{8-10}$

The embryonic fissure normally begins to close around the end of the fourth week of intrauterine life, and the closure proceeds anteriorly and posteriorly. Because the portion of the embryonic fissure in the region of the optic papilla is the last to close, isolated colobomas of the optic nerve head are not uncommon. ${ }^{11-20}$ These may be partial or complete and may be inherited usually as an autosomal dominant trait. ${ }^{21-23}$

The following case presents the problems of diagnosis of Coats's disease especially when it is combined with another rare anomaly such as morning glory type of optic disc coloboma.

\section{Case report}

A 13-year-old girl was admitted to our department with a longstanding neovascular glaucoma of her right eye. She suffered from congenital esotropia in this eye and underwent stabismus operation in

Correspondence to Dr I Kremer, Department of Pathology, c/o Professor A Garner, Institute of Ophthalmology, 17-25 Cayton Street, London EC1V 9AT. another hospital when she was 1-year-old. Her medical file from that hospital showed that she suffered from organic amblyopia in this eye, and its visual acuity was never more than $1 / 60$. The abnormal findings found then were morning glory type of optic disc anomaly with gliosis of optic nerve head and peripapillary pigmentary changes, and severe degenerative changes in the inferotemporal periphery with neovascularisation in that area. There was no family history of eye diseases.

On admission the visual acuity was uncertain light projection in the right eye and $6 / 6$ in the left one. The intraocular pressure was $40 \mathrm{mmHg}$ in the right eye and $12 \mathrm{mmHg}$ in the left. The right eye presented

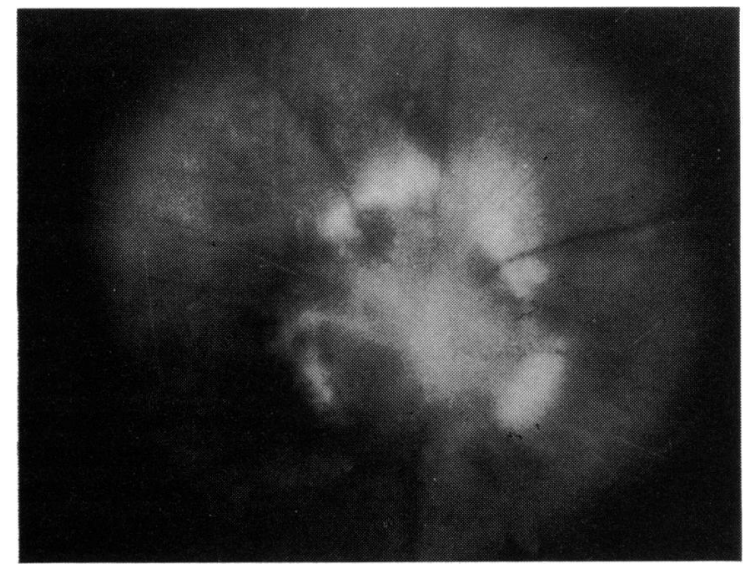

Fig. 1 Morning glory type of optic disc coloboma with central gliotic mass. 


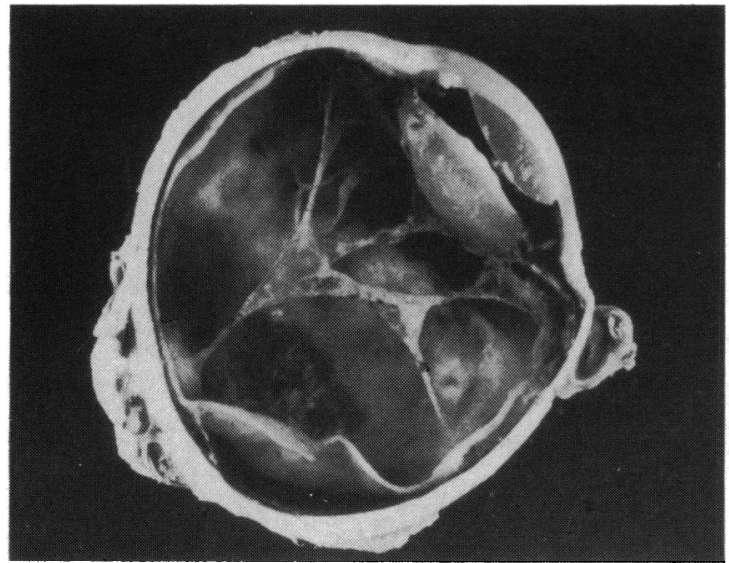

Fig. 2 Macroscopic picture of central vitreous strands extending from the disc to the ciliary body and lens.

ciliary and conjunctival injection, a diffuse corneal oedema with some old keratic precipitates in the endothelium, and a deep anterior chamber. Rubeosis iridis with ectropion uvea and cataractous lens were also noted. Funduscopy showed a pale disc with a big central excavation filled with a gliotic mass (Fig. 1). No central retinal artery or vein was seen, and instead there were several blood vessels leaving the disc as seen in morning glory syndrome. Perivascular sheathing was observed near the optic disc. Temporal to the macula there were confluent subretinal yellow exudates with slight raising of the sensory retina and

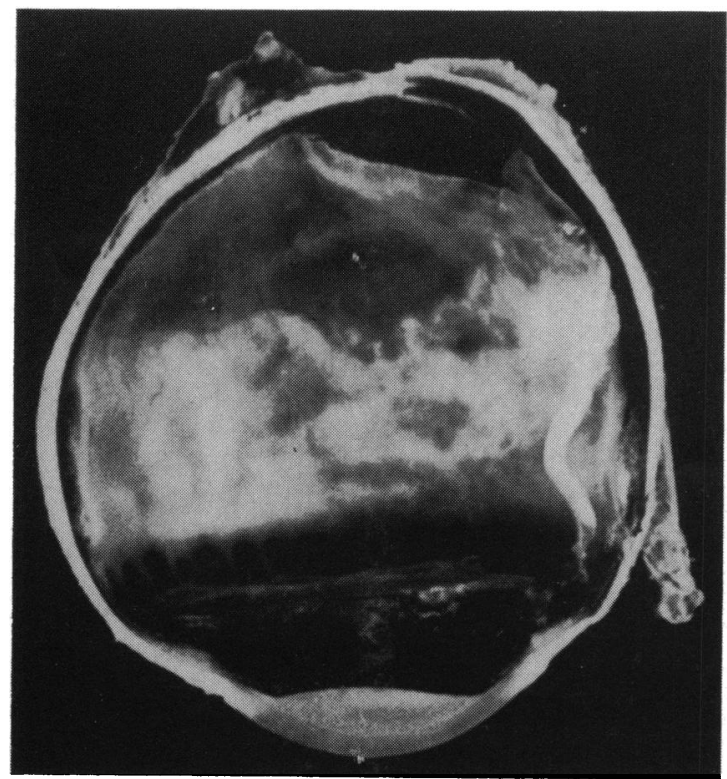

Fig. 3 Macroscopic picture of a wide yellow band of subretinal exudation at the equatorial region.

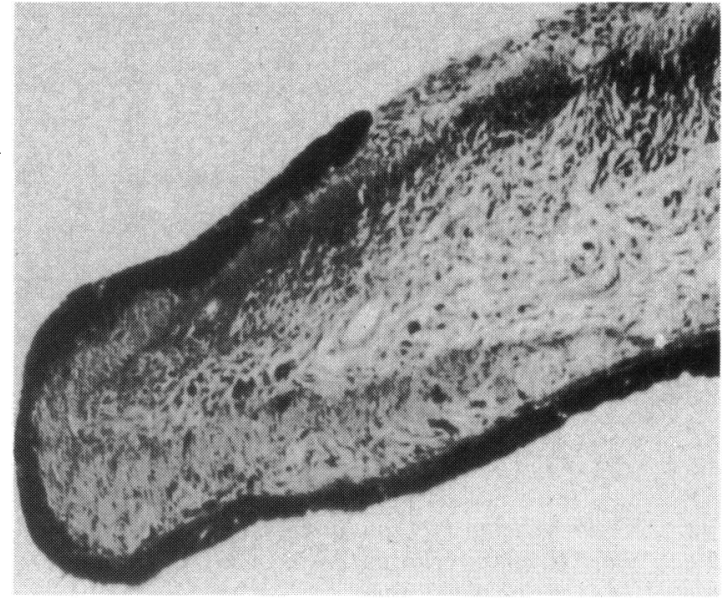

Fig. 4 Ectropion uveae with rubeosis iridis. (Haematoxylin and eosin, $\times 120$ ).

many capillary loops. Retinal haemorrhages were found in the lower temporal quadrant.

Gonioscopy showed a closed anterior chamber angle in the right eye and an open angle in the left one. The left eye appeared normal. In spite of maximal treatment 'with atropine, Dexamycin (dexamethasone), timolol maleate, and Diamox (acetazolamide) the intraocular pressure did not go down, and the patient underwent cyclocryotherapy in two sessions. This treatment did not lower the pressure either and, because the patient suffered from severe pain, we decided to enucleate the right eye. In order to rule out cerebral vascular malformations the patient underwent computerised axial tomography (CT) scanning of the skull, which was normal.

Pathological examination. The dimensions of the eyeball were $24 \times 21 \times 21 \mathrm{~mm}$ and it was hard on palpation. There was a limbal depression in the lower nasal quadrant, the cornea looked clear, the anterior chamber deep, and the lens cataractous. Horizontal section was done, and fluid vitreous came out. Central vitreous strands extended from the optic disc to the ciliary body (Fig. 2). An $8 \mathrm{~mm}$ wide yellow band, slightly raised, was seen at the equatorial region extending to the ora serrata. Inferiorly it extended towards the macular area (Fig. 3). The optic disc appeared as a white raised mass. The macula was not clearly seen.

Microscopy. The corneal epithelium looked flat. A peripheral pannus was found, and the endothelial cells were vacuolated. In the iris there was ectropion uveae with a thick fibrovascular membrane on the anterior face (Fig. 4). Peripheral anterior synechiae were present all around. The ciliary body was atrophic, and a thick cyclitic membrane was seen in 


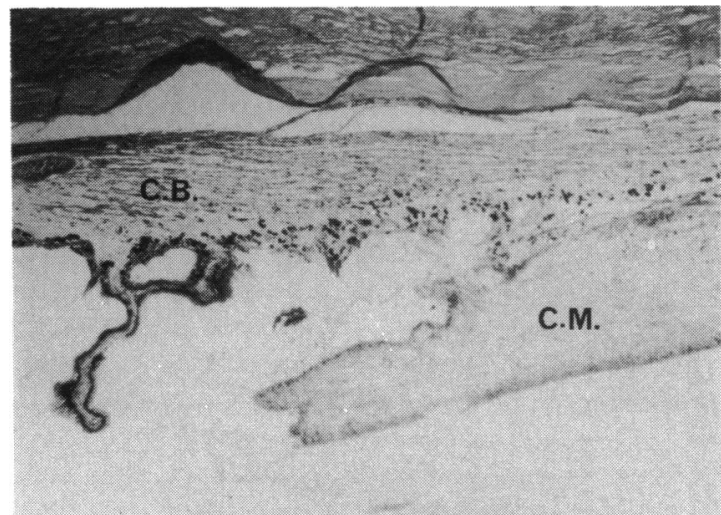

Fig. 5 A thick cyclitic mebrane adherent to posterior half of ciliary body (Haematoxylin and eosin, $\times$ 53). CB = ciliary body. $\mathrm{CM}=$ cyclitic membrane.

its posterior half (Fig. 5). The choroid looked normal except for a marked congestion of its blood vessels.

Temporally the retina was detached with conglomerates of lipid laden macrophages in the subretinal fluid and in the external retinal layers (Fig. 6). On the same side of the retinal detachment the retina was thickened by glial proliferation associated with many thick walled and tortuous vessels. Some of them were obstructed by a hyaline material (Fig. 7). Posterior to this vascular anomaly the retina was covered internally by a thick fibrovascular membrane causing fixed folds. Temporally the retina was markedly vacuolated and atrophic. In other areas the detached retina showed a moderate atrophy with no vascular pathology. At the region of the optic disc the retina together with the retinal pigment epithelium (RPE) penetrated deep into the excavation of the

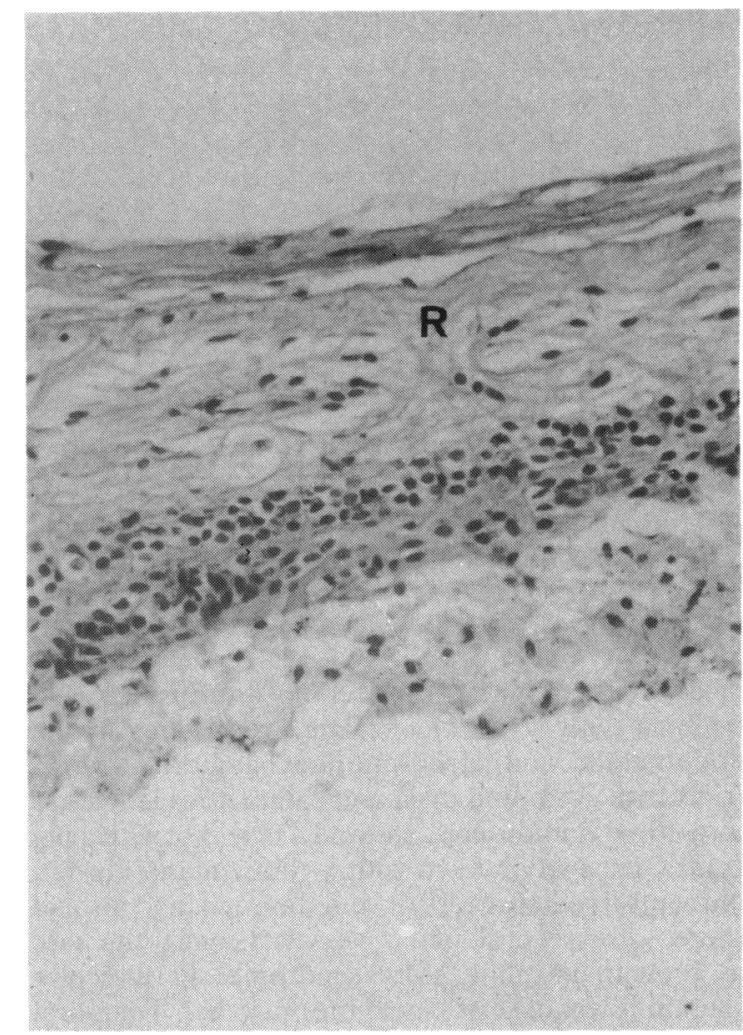

Fig. 6 Detached retina with lipid laden macrophages mainly in subretinal space. (Haematoxylin and eosin, $\times 240$ ).

disc (Fig. 8) and filled the excavation, at the centre of which some retinal vessels were visible (Fig. 9). At the border of the excavation the RPE cells showed hyperplasia and formed a thick metaplastic connec-

Fig. 7 Thickened detached retina $\mathbf{R}$ with glial proliferation, thick walled vessels $\mathrm{V}$, and preretinal fibrosis (Haematoxylin and eosin, $\times 185)$.

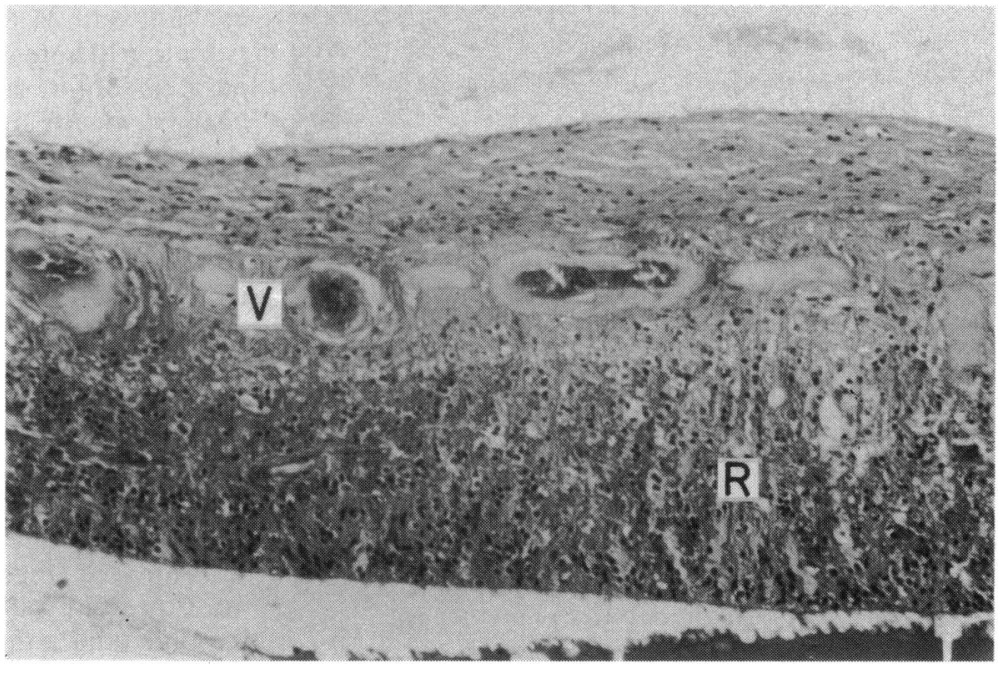




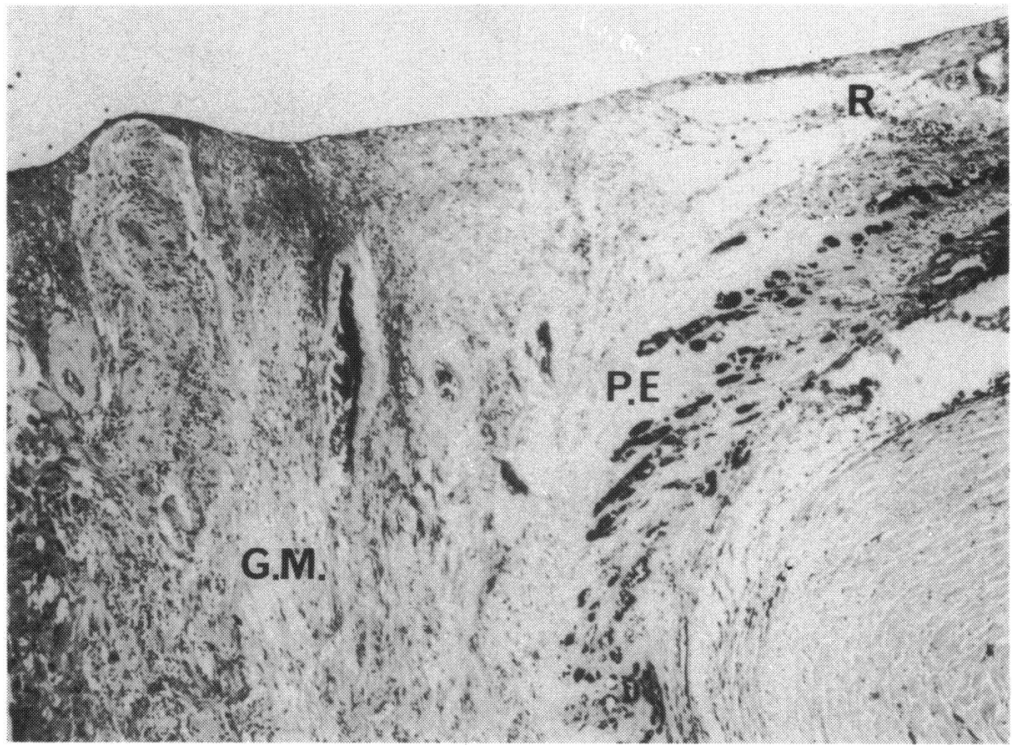

Fig. 8 The retina together with retinal pigment epithelium $(R P E)$ are penetrating into the periphery of the disc excavation. A large gliotic mass is seen in the centre. $\mathbf{R}=$ retina. $P E=$ pigment epithelium $\mathrm{GM}=$ gliotic mass. (Haematoxylin and eosin, $\times 46$ ).

tive tissue (Fig. 10). Thick walled vessels from the optic disc excavation extended into the peripapillary retina.

\section{Discussion}

Coats's disease is characterised clinically by sheets of subretinal exudation and foci of irregularly dilated capillaries, large microaneurysms, and bizarre configurations of dilated vascular channels. Subretinal haemorrhage, sometimes extensive, is mixed with exudation. Mounds of detached retina solidly raised by massive subretinal fatty exudation and haemorrhage may develop at different stages of the disease.$^{24-25}$ The disease may reach a certain stage and spontaneously regress with retinal and subretinal neovascular fibrosis with fixed retinal folds, or it may proceed to rubeosis iridis, neovascular glaucoma, and eventual loss of the eye, ${ }^{25}$ as happened in our case. The primary lesion is thought to be abnormal permeability of the retinal vessels. The vessel walls are badly damaged which causes aneurysmic dilatation, transudation of serum with lipids, haemorrhages and occlusion of blood vessels, mainly

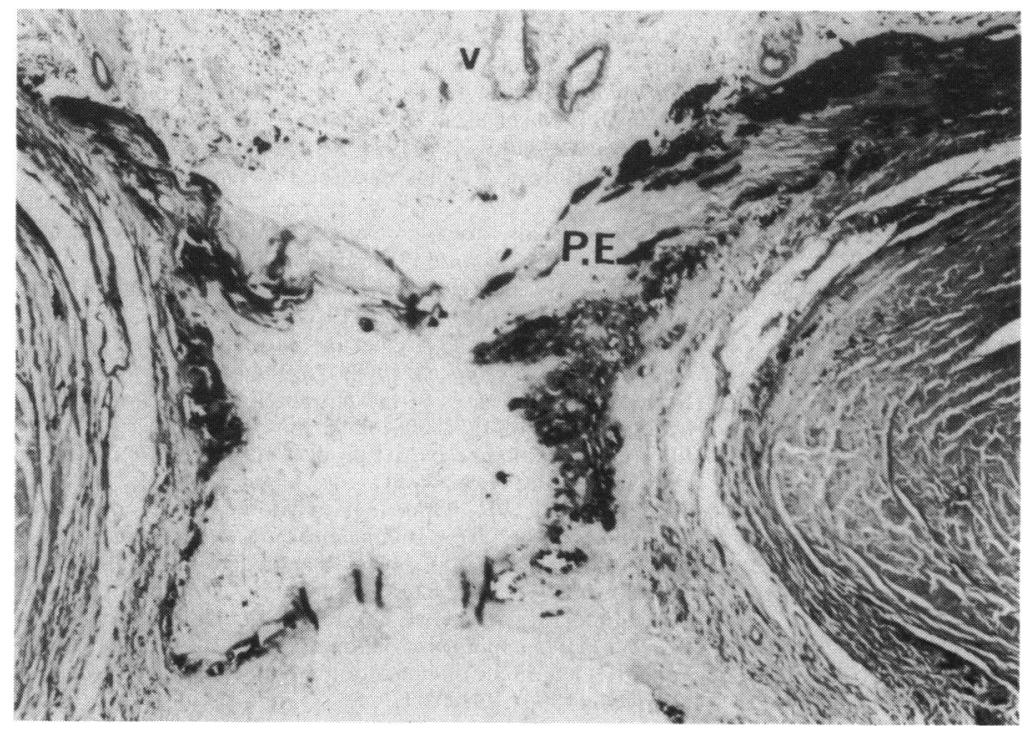

Fig. 9 Proliferating RPE cells penetrate deep into the excavation of the optic disc. Some retinal vessels $\mathrm{V}$ are seen. $\mathrm{PE}=$ pigment epithelial cells. (Haematoxylin and eosin, $\times 80$ ). 
Fig. 10 At the border of the excavation the RPE cells PE form a thick metaplastic connective tissue (Haematoxylin and eosin, $\times 111$ ).

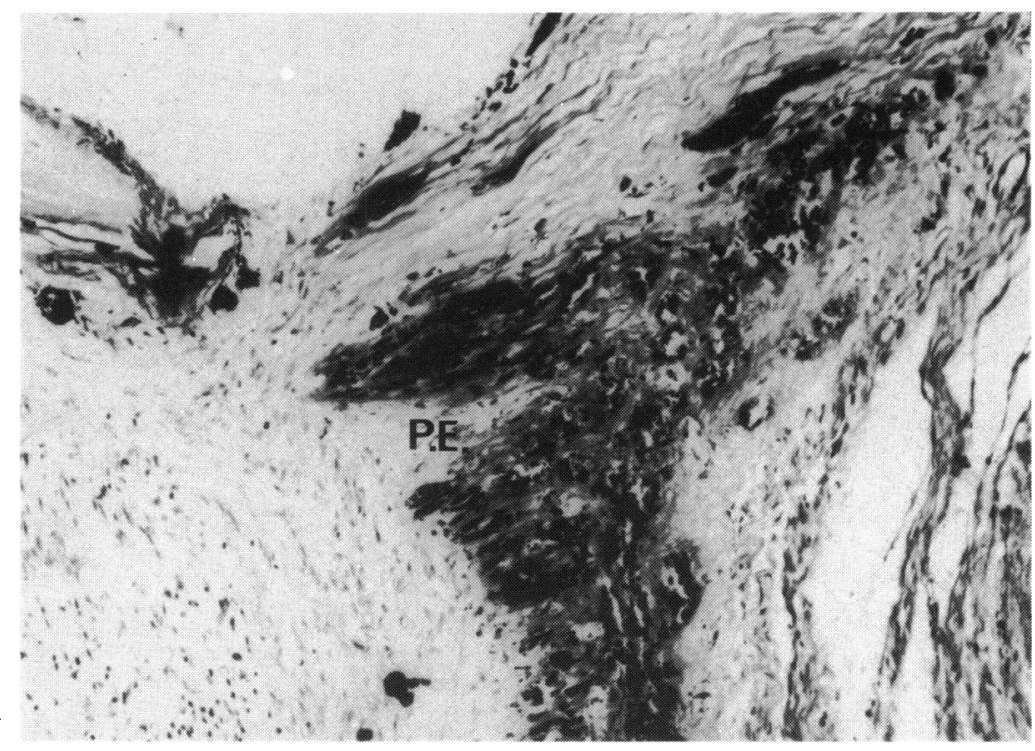

peripherally. Subretinally there are massive periodic acid Schiff-(PAS) - positive fatty exudation, lipidladen ('foamy') macrophages, cholesterol crystals, and red blood cells. ${ }^{26-27}$ The origin of the 'foamy' macrophages is not clear. They probably arise from retinal macrophages and, doubtfully, from retinal pigment epithelial cells. ${ }^{28}$ Coloboma of the nerve head is a congenital defect that may show as a cavity confined to the disc, or the cavity may also be present in the line of the cleft below the disc. There is apparently no sharp dividing line between cases of coloboma of the nerve head and crater-like holes in the disc. Cogan ${ }^{19}$ and François ${ }^{14}$ have shown that the affected part of the disc, usually the lower, is replaced by a large mass of incompletely organised tissue containing retinal and mesodermal elements. It resembles a fold of retina which has been pushed back into the lower part of the sclerochoroidal foramen causing distortion of the nerve head. Calhoun ${ }^{21}$ described a histopathological case that was similar to the picture described in our case, in which a hole in the disc communciated with an extensive cavity containing retinal elements and passing between sclera and the optic nerve sheath.

In the above case we have found a combination of Coats's disease as a retinal vascular anomaly and optic disc coloboma associated with abnormality of the main blood vessels arrangement at the disc, as seen in morning glory syndrome. We wonder if there is any correlation between these two vascular anomalies, Coats's disease being mainly peripheral and morning glory syndrome being central. To the best of our knowledge there is no record of a similar case combining these two rare anomalies, and there- fore we decided to describe this very rare and most probably coincidental association.

\section{References}

1 Coats G. Forms of retinal diseasc with massive exudation. $R$ London Ophthalmic Hosp Rep 1908; 17: 440)-525.

2 Coats G. Über retinitis exudativa (Retinitis hacmorrhagica externa). Albrecht von Graefes Arch Klin Ophthalmol 1912; 81: 275-327.

3 Woods AC, Duke JR. Observations on Coats' discase. Trans Ophthalmol Soc UK 1962; 82: 105-21.

4 Egerer I, Tasman W, Tomer TL. Coats' disease. Arch Ophthalmol 1974; 92: 109-12.

5 Fox KR. Coats' disease. Metab Pediatr Ophthalmol 1980; 4: 121-4.

6 Reese AB. Telangiectasis of the retina and Coats' discasc. Am J Ophthalmol 1956; 42: 1-8.

7 Harris GS. Coats' disease, diagnosis and treatment. Can J Ophthalmol 1970; 5: 311-20.

8 Marshall J, Michaclson IC. Exudative retinitis in childhood. Trans Ophthalmol Soc UK 1933; 53: 102-18.

9 Wise GN, Horava A. Coats' disease. Am J Ophthalmol 1963; 56: 17-23.

10 Sugar HS. Coats' disease: telangiectatic or multiple vascular origin? Am J Ophthalmol 1958; 45: 508-17.

11 Kindler P. Morning glory syndrome: unusual congenital optic disc anomaly. Am J Ophthalmol 1970; 69: 376-84.

12 Gruner HJ, Fechner PU. Über das Morning Glory Syndrom. Klin Monatsbl Augenheilkd 1978; 172: 114-5.

13 Krause U. Three cases of the morning glory syndrome. Acta Ophthalmol (Kbh) 1972; 50: 188-98.

14 François J. Colobome particl du nerf optique. Bull Soc Belge Ophthalmol 1964; 138: 548-51.

15 Savell J, Cook JR. Optic nerve colobomas of autosomaldominant heredity. Arch Ophthalmol 1976; 94: 395-400.

16 Jensen PE, Kalina RE. Congenital anomalics of the optic disc. Am J Ophthalmol 1976; 82: 27-31.

17 Duke Elder S, Cook C. Embryology. In: Duke Elder S. ed. System of ophthalmology. London: Kimpton, 1963; 3(1): 38-40.

18 Pedler C. Unusual Coloboma of the optic nerve entrance. Br J Ophthalmol 1961; 45: 803-7. 
19 Cogan DG. Coloboma of optic nerve with overlay of peripapillary retina. Br J Ophthalmol 1978; 62: 347-50.

20 Hughes HL. Case of bilateral Coloboma of optic disc. Br J Ophthalmol 1947; 31 : 689-92.

21 Calhoun FP. Bilateral coloboma of optic nerve associated with holes in disc and cyst of optic sheath. Arch Ophthalmol 1930; 3: 71-9.

22 Bikle CE, Levitt JM. Coloboma of optic nerve. Am J Ophthalmol 1949; 32: 700-2.

23 Payne BF. Coloboma of optic nerve in human embryo Am J Ophthalmol 1941; 24: 395-402.
24 Farkas TG, Potts AM, Boonc C. Some pathologic and biochemical aspects of Coats' diseasc. Am J Ophthalmol 1973; 75: 289-301.

25 Meythaler $H$. Zur pathologischen anatomic der retinitis exsudativa externa. Klin Monatsbl Augenheilkd 1970; 156: 644.

26 Tripathi R, Ashton N. Electron microscopical study of Coats' discase. Br J Ophthalmol 1971; 55: 289-301.

27 Manschot WA, Bruijn WC de. Coats' discasc: definition and pathogenesis. BrJ Ophthalmol 1967; 51: 145-57.

28 Takei Y. Origin of ghost cell in Coats' discasc. Invest Ophthalmol Visual Sci 1976; 15: 677-81. 